\title{
Water-pipe (narguile) smokers in Lebanon: a pilot study
}

M. Waked, ${ }^{1}$ P. Salameh ${ }^{2}$ and Z. Aoun ${ }^{3}$

$$
\text { مدرخنو الشيشة (النارجيلة) في لبنان: دراسة ارتيادية }
$$

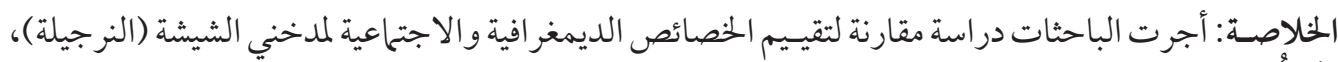

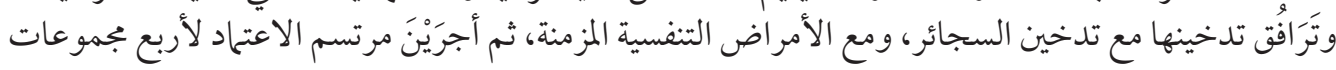

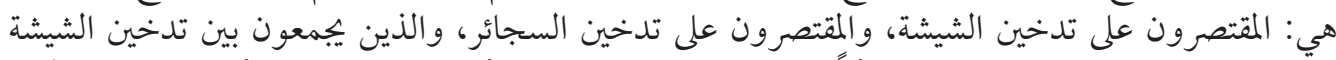

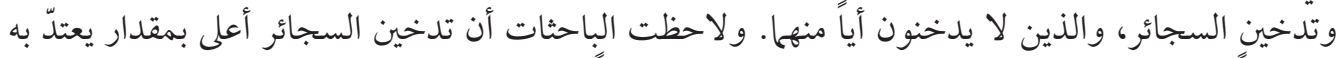

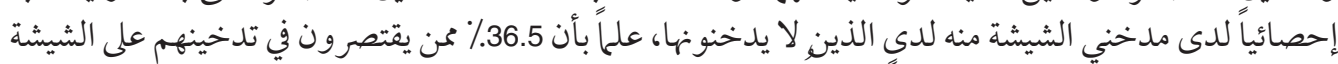

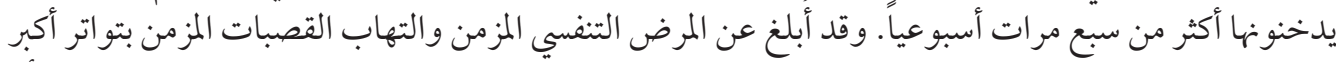

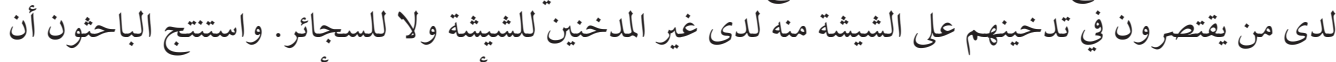

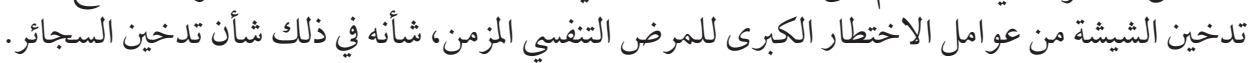

ABSTRACT We carried out a comparative study to assess the demographic and social characteristics of water pipe (WP) smokers, the association with cigarette smoking and chronic respiratory diseases and the dependence profile on 4 groups: exclusive WP smokers, exclusive cigarette smokers, mixed smokers and absolute non-smokers. Cigarette smoking was statistically significantly higher in WP smokers than non-WP smokers; $36.5 \%$ of exclusive WP smokers smoked $\geq 7 \mathrm{WPs} /$ week. Chronic respiratory disease and chronic bronchitis were reported more frequently in exclusive WP smokers than absolute non-smokers. WP smoking seems to be as great a risk factor as cigarette smoking for chronic respiratory disease.

\section{Fumeurs de narguilé (pipe à eau) au Liban : une étude pilote}

RÉSUMÉ Nous avons réalisé une étude comparative afin d'évaluer les caractéristiques démographiques et sociales des fumeurs de narguilé, le lien avec la consommation de cigarettes et les maladies respiratoires chroniques, et le type de dépendance de quatre groupes : des sujets fumant uniquement le narguilé, des sujets fumant uniquement des cigarettes, des sujets fumant les deux et des sujets ne fumant pas du tout. La consommation de cigarettes était significativement plus élevée du point de vue statistique chez les sujets qui fumaient le narguilé que chez les autres ; $36,5 \%$ des sujets fumant uniquement le narguilé en fumaient au moins sept par semaine. On signalait davantage de maladies respiratoires chroniques et de bronchite chronique chez les sujets fumant uniquement le narguilé que chez les non-fumeurs. La consommation de narguilé semble être un facteur de risque de maladie respiratoire chronique aussi important que la consommation de cigarettes.

\footnotetext{
${ }^{1}$ Department of Pulmonology, St George University Hospital, Beirut, Lebanon.

${ }^{2}$ Department of Public Health, Faculty of Public Health, Lebanese University, Beirut, Lebanon

(Correspondence to P. Salameh: pascalesalameh@yahoo.com).

${ }^{3}$ Department of Pulmonology, Hotel-Dieu Hospital, Beirut, Lebanon.

Received:08/06/06; accepted: 13/09/06
}

المجلة الصحية لشرق المتوسط، منظمة الصحة العالمية، المجلد الخامس عشر، العدد ب، 9 ·. 


\section{Introduction}

Recently, water pipe (WP) (also known as hubble-bubble, hookah, narghile, and shisha) smoking has become fashionable and is extensively used in the Middle East [1-3], particularly Lebanon [4], and even in Europe and the United States of America [3,5].

A common belief in the general population is that WP smoking is less harmful than cigarette smoking because the water filters the smoke [1] and because the tobacco contains "healthy" fruits [6]. Smoke filtered by water is freed from substances like acrolein (2-propenal) and phenols; the nicotine level, however, remains unchanged [7].

Narghile smoke probably contains several of the chemicals thought to be causal factors of cancer, cardiovascular disease and dependence in cigarette smokers [8]. Some studies described lower birth weights in babies of mothers who smoke WPs [9]. Others noted impairment of pulmonary function on spirometry [10], association with cancers [11], and increased pulmonary epithelial permeability [12]. Taken together, these reports suggest that WP smoking has a deleterious effect on health as well as inducing dependence on nicotine similar to that found in cigarette use.

Since few data exist regarding WP smoking in Lebanon, the objective of this pilot study was to assess the demographic and social characteristics of WP smokers compared to non-WP smokers, the association between cigarette smoking and WP smoking, the association between WP smoking and chronic respiratory disease and the nicotine dependence profile of WP smokers. This pilot study is a part of a larger project on WP use in Lebanon that is designed to further evaluate nicotine and carbon monoxide levels and nicotine dependence in smokers, and respiratory diseases related to WP smoking.

\section{Methods}

This was a comparative study of exclusive WP smokers with cigarette smokers, mixed smokers and absolute non-smokers. It was not intended to calculate the overall prevalence of WP smoking in Lebanon.

\section{Study population}

Inclusion criteria were being Lebanese, aged $\geq 16$ years and being a regular WP smoker (defined as current smoking of $\geq 1$ WP per week) or a non-WP smoker.

\section{Data collection}

Data were collected by telephone interview. A list of active numbers for the whole of Lebanon was provided by the national telephone company. We randomly selected 1 per 1000 and the interviewers called the numbers with the aim of recruiting a minimum of 161 regular WP smokers and 242 non-WP smokers. This would allow for an odds ratio (OR) of at least 2.50 between WP smoking and chronic cough or expectoration, with an alpha risk of $5 \%$ and a power of $80 \%$, assuming that WP smoking is responsible for as much chronic cough and expectoration as cigarette smoking and that prevalence of these chronic symptoms is $20 \%$ in smokers [13].

The interviewer gave a brief introduction to the objective of the study, and explained it as being a study regarding WP smoking. After verbal consent to participate, the person who answered the call was asked if he/she was eligible and a regular WP smoker: if yes, the interview was carried out with him/her. If not, he/she was asked if any present family member was a regular WP smoker and eligible: if yes, this family member was interviewed. If more than one family member were WP smokers, the one sitting closest to the phone was interviewed. If the WP smoker was absent at the time of

المجلة الصحية لشرق المتوسط، منظمة الصحة العالمية، المجلد الخامس عشر، العلد Y، 9 +. 
the call, an appointment was made to call again. If there were no regular WP smokers among family members, the interview was carried out with the person who answered the phone or the eligible family member closest to the phone. If no family members were eligible at all, the household was replaced by the next one on the list. Thus, the selected regular WP smokers represented Lebanese households where there was $\geq 1$ regular WP smoker, while the group of nonWP smoker represented households which had no regular WP smokers.

Data were collected using a standardized Arabic questionnaire that was developed especially for this study. It included questions on socioeconomic factors, history of active and passive smoking, chronic bronchitis and respiratory diseases, and dependence profile. The names of the participants were not registered on the database to ensure confidentiality.

WP smoking, chronic bronchitis and respiratory disease constituted dependent variables. WP smoking was assessed by the number smoked per week and the duration of smoking. Frequency was divided into 4 exposure classes: $0,1,2-6$ and $\geq 7$ WPs per week. Using a method similar to that used to calculate cumulative exposure to cigarette smoking, cumulative WP smoking was calculated by multiplying the number smoked per week by the duration of WP smoking; the product was divided into 4 cumulative exposure classes: non-smokers, 1-3 WP years, 4-28 WP years and > 28 WP years. These classifications were chosen to obtain equivalent cumulative percentages per class of consumption.

Respiratory disease was assessed by a positive answer regarding physiciandiagnosed chronic respiratory disease (PDRD). Chronic bronchitis was defined as having a morning productive cough for $>3$ months a year for $>2$ years [14].
Independent variables were age, sex, height, weight, body mass index $\left(\mathrm{kg} / \mathrm{m}^{2}\right)$, education, professional status, marital status, active cigarette smoking and passive smoking.

Education was evaluated according to the years of schooling with 0-8 years considered low education, 9-15 years intermediate, and being a university student or graduate high education. Residing in a city, town or village was self-assessed. Being an active cigarette smoker was defined as smoking $\geq 1$ cigarette per day. Passive smoking was evaluated by the number of smokers at home and at work. The dependence profile was evaluated by adapting the Fagerström test and DSM-IV items for nicotine dependence items to WP smoking $[15,16]$.

\section{Data analysis}

Data entry and analyses were performed using SPSS, version 12.0. Two-tailed statistical tests were used: chi-squared test for categorical variables and Mann-Whitney and Kruskal-Wallis tests for continuous variables of non-homogeneous variables or non-normal distribution, and analysis of variance was used for continuous variables with normal distribution.

Tukey post-hoc comparison tests were used to allow for 2 by 2 group comparisons. A trend test was applied for doseeffect relationships between frequency of WP smoking and cumulative WP smoking on the one hand, and chronic respiratory disease and chronic bronchitis on the other.

In addition, multivariate analysis was done: backward stepwise logistic regression for WP smoking, chronic bronchitis and respiratory diseases, with adjustment for potential confounding variables (age, sex, body mass index, education, work status, marital status, active cigarette smoking, and passive smoking). 


\section{Results}

\section{Sociodemographic characteristics}

From 448 phone calls, 425 questionnaires were completely filled and analysed; a refusal rate of $5.1 \%$ was noted. There were significant differences regarding all baseline characteristics $(P<0.001)$ except for marital status. The majority of non-smokers were women and the majority of mixed smokers men (Table 1). Mean age was highest for cigarette smokers; mixed smokers were more obese than the other groups. All groups included highly educated individuals. Compared with other groups of smokers, more of the exclusive cigarette smokers had low education. About $75 \%$ of mixed smokers were currently working, while about half of the cigarette smokers were not working (Table 1).

\section{Smoking characteristics}

Non-smokers had a statistically significantly lower number of smokers at home $(P<0.001)$; cigarette smoking was more

Table 1 Sociodemographic characteristics of smokers and non-smokers in Lebanon

\begin{tabular}{|c|c|c|c|c|c|c|c|c|c|c|c|}
\hline \multirow[t]{3}{*}{ Variable } & \multicolumn{8}{|c|}{ Type of smoker } & \multirow[t]{3}{*}{$P$-value } & \multirow{2}{*}{\multicolumn{2}{|c|}{$\begin{array}{c}\text { Total } \\
(n=425)\end{array}$}} \\
\hline & \multicolumn{2}{|c|}{$\begin{array}{c}\text { Non-smokers } \\
\quad(n=183)\end{array}$} & \multicolumn{2}{|c|}{$\begin{array}{l}\text { Cigarettes } \\
(n=81)\end{array}$} & \multicolumn{2}{|c|}{$\begin{array}{c}\text { WP } \\
(n=75)\end{array}$} & \multicolumn{2}{|c|}{$\begin{array}{c}\text { Mixed } \\
(n=86)\end{array}$} & & & \\
\hline & No. & $\%$ & No. & $\%$ & No. & $\%$ & No. & $\%$ & & No. & $\%$ \\
\hline \multicolumn{12}{|l|}{ Sex } \\
\hline Male & 71 & 38.8 & 44 & 54.3 & 36 & 48.0 & 61 & 70.9 & \multirow[t]{2}{*}{$<0.001$} & 212 & 49.9 \\
\hline Female & 112 & 61.2 & 37 & 45.7 & 39 & 52.0 & 25 & 29.1 & & 213 & 50.1 \\
\hline \multicolumn{12}{|l|}{ Marital status } \\
\hline Unmarried & 90 & 49.2 & 27 & 33.3 & 39 & 52.0 & 37 & 43.0 & \multirow[t]{2}{*}{0.06} & 193 & 45.4 \\
\hline Married & 93 & 50.8 & 54 & 66.7 & 36 & 48.0 & 49 & 57.0 & & 232 & 54.6 \\
\hline \multicolumn{12}{|l|}{ Education } \\
\hline Low & 8 & 4.4 & 16 & 19.8 & 13 & 17.3 & 9 & 10.5 & \multirow{3}{*}{$<0.001$} & 46 & 10.8 \\
\hline Intermediate & 72 & 39.3 & 42 & 51.9 & 27 & 36.0 & 29 & 33.7 & & 170 & 40.0 \\
\hline High & 103 & 56.3 & 23 & 28.4 & 35 & 46.7 & 48 & 55.8 & & 209 & 49.2 \\
\hline \multicolumn{12}{|l|}{ Work situation } \\
\hline Working & 90 & 49.5 & 35 & 43.2 & 41 & 54.7 & 64 & 74.4 & \multirow[t]{3}{*}{$<0.001$} & 230 & 54.2 \\
\hline Not working & 63 & 34.6 & 41 & 50.6 & 25 & 33.3 & 16 & 18.6 & & 145 & 34.2 \\
\hline Student & 29 & 15.9 & 5 & 6.2 & 9 & 12.0 & 6 & 7.0 & & 49 & 11.6 \\
\hline \multicolumn{12}{|l|}{ Residence } \\
\hline City & 113 & 61.7 & 39 & 48.1 & 50 & 66.7 & 52 & 60.5 & \multirow[t]{4}{*}{$<0.001$} & 254 & 59.8 \\
\hline Town & 66 & 36.1 & 31 & 38.3 & 24 & 32.0 & 21 & 24.4 & & 142 & 33.4 \\
\hline \multirow[t]{2}{*}{ Village } & 4 & 2.2 & 11 & 13.6 & 1 & 1.3 & 13 & 15.1 & & 29 & 6.8 \\
\hline & Mean & SD & Mean & SD & Mean & SD & Mean & SD & & Mean & SD \\
\hline$A g e^{b}$ (years) & 35.9 & 15.6 & 48.6 & 17.1 & 35.4 & 15.9 & 39.6 & 14.5 & $<0.001$ & 39.0 & 16.4 \\
\hline Weightc (kg) & 68.3 & 13.9 & 73.0 & 14.3 & 71.0 & 14.8 & 79.1 & 12.2 & $<0.001$ & 71.8 & 14.4 \\
\hline Height $^{d}(m)$ & 168.6 & 9.0 & 170.2 & 9.1 & 170.4 & 9.5 & 174.0 & 8.4 & 0.001 & 170.3 & 9.2 \\
\hline$B M I^{e}\left(\mathrm{~kg} / \mathrm{m}^{2}\right)$ & 23.9 & 4.1 & 25.1 & 3.9 & 24.4 & 4.7 & 26.2 & 3.6 & $<0.001$ & 24.7 & 4.2 \\
\hline
\end{tabular}

${ }^{a}$ Total > 183 as some students also had jobs.

${ }^{b}$ Age Tukey post-hoc tests: non-smoker $=$ WP smoker $=$ mixed smoker < cigarette smoker.

cWeight Tukey post-hoc tests: non-smoker < cigarette smoker = WP smoker < mixed smoker.

${ }^{d}$ Height Tukey post-hoc tests: non-smoker = cigarette smoker $=$ WP smoker $<$ mixed smoker.

${ }^{e} B M I$ Tukey post-hoc tests: non-smoker < cigarette smoker $=$ WP smoker < mixed smoker.

$W P=$ water pipe; $S D=$ standard deviation; $B M I=$ body mass index .

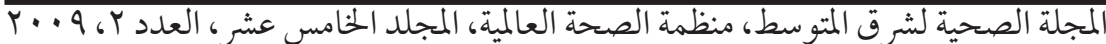


common when there were a higher number of smokers at work. Exclusive cigarette smokers consumed more cigarettes per day and had been smoking for a longer period of time than mixed smokers. Exclusive WP smokers consumed a higher mean number of WPs per week than mixed smokers for an equivalent duration, thus had a higher cumulative exposure. However, there were no significant differences between the 2 groups regarding the number of people who would regularly share the WP and the size of the WP (small/medium/large: standard sizes on the market in Lebanon). Mixed smokers inhaled the smoke significantly more often than exclusive WP smokers (Table 2). Comparing all WP smokers with non-WP smokers, there were more cigarette smokers in the WP group $(52.5 \%$ vs $28.0 \%)(P<0.0001)$. Mean age for starting WP smoking was 16 years. The following reasons were given for smoking WP: pleasure $(52.5 \%)$, conviviality $(24.7 \%)$ and habit $(10.8 \%)$. The majority of WP smokers $(61.6 \%)$ had smoked for $<5$ years (results not shown).

\section{Nicotine dependence profile}

A higher percentage of mixed smokers than exclusive WP smokers stated that the first WP of the day would be the most difficult to give up, and a higher number of exclusive WP smokers would leave the family on a holiday to go and buy WP tobacco $(P$ $=0.04)$. More exclusive WP smokers had their first WP less than 1 hour after wakingup (Table 3) $(P=0.04)$. For other criteria related to nicotine dependence, there was no significant difference between exclusive WP smokers and mixed smokers.

\section{Respiratory disease}

There were significant differences regarding PDRD, particularly for chronic bronchitis, asthma and respiratory allergy. Exclusive
WP smokers and mixed smokers had more PDRD than cigarette smokers, and much more than non-smokers. In parallel with mucolytic use, symptoms of chronic bronchitis were mostly reported by mixed smokers $(41.9 \%)$, followed by cigarette smokers (37.0\%); the difference between WP and cigarette smokers was not statistically significant $(P>0.20)$ (Table 4$)$.

For dose-effect relationships, a higher frequency of WP smoking and cumulative exposure were statistically significantly associated with higher risk of having chronic bronchitis and PDRD (Table 5).

\section{Multivariate analysis}

In multivariate analysis (Table 6), WP smoking was correlated with older age, currently working, number of smokers at home, active cigarette smoking and lower education.

For the presence of PDRD, WP smoking was a risk factor [adjusted $\mathrm{OR}\left(\mathrm{OR}_{\mathrm{a}}\right)=1.95$ ], along with the number of smokers at home and marital status. WP $\left(\mathrm{OR}_{\mathrm{a}}=1.89\right)$ and cigarette smoking $\left(\mathrm{OR}_{\mathrm{a}}=2.62\right)$ were both correlated to reported chronic bronchitis, in addition to older age, city residence, lower and intermediate education.

Use of mucolytics to treat chronic cough was associated with WP smoking (OR $=3.07)$ and cigarette smoking $\left(\mathrm{OR}_{\mathrm{a}}=1.45\right.$; $P>0.05)$. Village residence and higher education were also retained in the model as associated with this behaviour.

\section{Discussion}

The mean age of exclusive WP smokers in our study was 35.4 years, and $46.7 \%$ were university graduates, which is concordant with previous studies done in Lebanon [1719]. There were as many males and females in exclusive WP smokers (52\%), indicating 
Table 2 Active and passive smoking characteristics in smokers and non-smokers in Lebanon

\begin{tabular}{|c|c|c|c|c|c|c|c|c|c|c|c|}
\hline \multirow[t]{3}{*}{ Variable } & \multicolumn{8}{|c|}{ Type of smoker } & \multirow[t]{3}{*}{$P$-value } & \multirow{2}{*}{\multicolumn{2}{|c|}{$\begin{array}{c}\text { Total } \\
(n=425)\end{array}$}} \\
\hline & \multicolumn{2}{|c|}{$\begin{array}{c}\text { Non- } \\
\text { smokers } \\
(n=183)\end{array}$} & \multicolumn{2}{|c|}{$\begin{array}{c}\text { Cigarettes } \\
(n=81)\end{array}$} & \multicolumn{2}{|c|}{$\begin{array}{c}\text { WP } \\
(n=75)\end{array}$} & \multicolumn{2}{|c|}{$\begin{array}{c}\text { Mixed } \\
(n=86)\end{array}$} & & & \\
\hline & Mean & SD & Mean & SD & Mean & SD & Mean & SD & & Mean & SD \\
\hline $\begin{array}{l}\text { No. of smokers at } \\
\text { home }^{a, b}\end{array}$ & 0.7 & 1.0 & 1.6 & 1.2 & 1.8 & 1.3 & 1.9 & 1.1 & $<0.001$ & 1.3 & 1.2 \\
\hline $\begin{array}{l}\text { No. of smokers at } \\
\text { work } k^{b, c}\end{array}$ & 0.4 & 1.3 & 1.5 & 2.8 & 0.9 & 2.2 & 1.8 & 2.6 & $<0.001$ & 1.0 & 2.2 \\
\hline No. of cigarettes/dayb & NA & & 22.4 & 17.8 & NA & & 20.8 & 15.5 & $<0.001$ & 8.5 & 14.8 \\
\hline $\begin{array}{l}\text { Duration of cigarette } \\
\text { smoking }^{b}\end{array}$ & NA & & 21.9 & 15.6 & NA & & 14.9 & 11.9 & $<0.001$ & 7.2 & 12.6 \\
\hline No. WP/week ${ }^{b}$ & NA & & NA & & 5.5 & 7.0 & 3.6 & 3.7 & 0.03 & 4.5 & 5.5 \\
\hline $\begin{array}{l}\text { Duration of WP } \\
\text { smoking }^{b}\end{array}$ & NA & & NA & & 7.7 & 10.9 & 6.4 & 7.0 & 0.37 & 7.0 & 9.0 \\
\hline Cumulative dose ${ }^{b}$ & NA & & NA & & 68.2 & 168.2 & 23.6 & 37.4 & 0.02 & 44.3 & 120.0 \\
\hline No of persons sharing ${ }^{b}$ & NA & & NA & & 1.7 & 1.2 & 1.5 & 1.3 & 0.39 & 1.6 & 1.2 \\
\hline & & & & & No. & $\%$ & No. & $\%$ & & No. & $\%$ \\
\hline Persons smoking: & NA & & NA & & & & & & & & \\
\hline 1 WP/week & & & & & 26 & 35.1 & 23 & 28.0 & 0.04 & 49 & 31.4 \\
\hline 2-6 WP/week & & & & & 21 & 28.4 & 42 & 51.2 & & 63 & 40.4 \\
\hline$\geq 7 \mathrm{WP} /$ week & & & & & 27 & 36.5 & 17 & 20.7 & & 44 & 28.2 \\
\hline Inhales WP smoke & NA & & NA & & & & & & & & \\
\hline Never & & & & & 51 & 68.0 & 26 & 31.3 & $<0.001$ & 77 & 48.7 \\
\hline Sometimes & & & & & 13 & 17.3 & 38 & 45.8 & & 51 & 32.3 \\
\hline Always & & & & & 11 & 14.7 & 19 & 22.9 & & 30 & 19.0 \\
\hline Size of WP & NA & & NA & & & & & & & & \\
\hline Small & & & & & 11 & 14.7 & 22 & 26.5 & 0.15 & 33 & 20.9 \\
\hline Medium & & & & & 54 & 72.0 & 54 & 65.1 & & 108 & 68.4 \\
\hline Large & & & & & 10 & 13.3 & 7 & 8.4 & & 17 & 10.8 \\
\hline
\end{tabular}

a Number of smokers at home Tukey post-hoc tests: non-smokers $<$ cigarette smokers $=$ WP smokers $=$ mixed smokers ${ }^{b}$ Mean and $S D$ are reported in groups of comparison.

'Number of smokers at work Tukey post-hoc tests: non-smokers $=$ WP smokers < cigarette smokers $=$ mixed smokers. Cumulative dose $=$ no. of WP weekly $\times$ duration (years).

$W P=$ water pipe; $S D=$ standard deviation; $N A=$ not applicable.

an increase in the prevalence of smoking among females from $13 \%$ in 1992-93 [20]. Despite WP smoking being time-consuming, $55 \%$ of WPS were currently working; the $33 \%$ who were not working comprised mainly women at home, who socialized by smoking WPs. This epidemic-like rise in WP smoking seems to predominate in urban areas since $67 \%$ of WP smokers lived in cities.

The majority of WP smokers $(61.6 \%)$ had smoked for less than 5 years, indicating the recent nature of the trend.

Living with smokers at home was associated with WP smoking, showing the incentive effect of this habit on people 
Table 3 Nicotine dependence profile in water pipe smokers in Lebanon

\begin{tabular}{|c|c|c|c|c|c|c|c|}
\hline \multirow[t]{2}{*}{ Variable } & \multicolumn{2}{|c|}{$\begin{array}{l}\text { WP smoker } \\
\quad(n=75)\end{array}$} & \multicolumn{2}{|c|}{$\begin{array}{l}\text { Mixed smoker } \\
\quad(n=86)\end{array}$} & \multirow[t]{2}{*}{$P$-value } & \multicolumn{2}{|c|}{$\begin{array}{c}\text { Total } \\
(n=161)\end{array}$} \\
\hline & Mean & SD & Mean & SD & & Mean & SD \\
\hline No. of days can stay without WP & 21.0 & 29.7 & 13.6 & 21.9 & 0.08 & 17.1 & 26.0 \\
\hline No. of times stopped WP for $>7$ days & 5.1 & 2.9 & 4.9 & 2.9 & 0.66 & 5.0 & 2.9 \\
\hline $\begin{array}{l}\text { Time spent searching for WP tobacco } \\
\text { (hours) }\end{array}$ & 8.4 & 21.2 & 5.5 & 15.4 & 0.36 & 7.0 & 18.5 \\
\hline Price ready to pay for WP tobacco (US\$) & 8.0 & 6.4 & 8.3 & 14.0 & 0.83 & 8.0 & 11.2 \\
\hline Age started regular WP smoking (years) & $\begin{array}{l}29.0 \\
\text { No. }\end{array}$ & $\begin{array}{c}11.8 \\
\%\end{array}$ & $\begin{array}{l}32.4 \\
\text { No. }\end{array}$ & $\begin{array}{l}12.0 \\
\%\end{array}$ & 0.07 & $\begin{array}{r}30.8 \\
\text { No. }\end{array}$ & $\begin{array}{r}12.0 \\
\%\end{array}$ \\
\hline Feeling disturbed if smoking not allowed & 20 & 27.4 & 18 & 22.2 & 0.46 & 38 & 24.7 \\
\hline Cannot give up the first WP of the day & 3 & 4.1 & 11 & 13.6 & 0.04 & 14 & 9.1 \\
\hline Smokes WP more in the morning & 9 & 12.3 & 8 & 9.9 & 0.63 & 17 & 11.0 \\
\hline Smokes WP even if very sick & 4 & 5.5 & 3 & 3.7 & 0.60 & 7 & 4.5 \\
\hline $\begin{array}{l}\text { Would leave the family on a holiday to } \\
\text { buy WP tobacco }\end{array}$ & 16 & 22.2 & 8 & 9.9 & 0.04 & 24 & 15.7 \\
\hline $\begin{array}{l}\text { Prefers WP to sport or other } \\
\text { activity }\end{array}$ & 28 & 38.4 & 23 & 28.4 & 0.19 & 51 & 33.1 \\
\hline $\begin{array}{l}\text { Ready not to eat but smoke WP } \\
\text { Delays smoking WP after waking up }\end{array}$ & 15 & 20.5 & 13 & 16.5 & 0.52 & 28 & 18.4 \\
\hline More than 1 hour & 66 & 90.4 & 74 & 91.4 & 0.04 & 140 & 90.9 \\
\hline Less than 1 hour & 7 & 9.5 & 7 & 8.6 & & 14 & 9.1 \\
\hline
\end{tabular}

Mean and standard deviation (SD) are reported in groups of comparison.

$W P=$ water pipe

in the same environment. In WP smokers, there were significantly more cigarette smokers compared with non-WP smokers. This might signify that WP smoking is a smoking behaviour per se: WP is one of the tobacco tools of smokers, not just a social habit [21,22]. Mixed smokers may regulate their nicotine intake by the amount consumed of each tobacco type. Chaouachi noted that people in countries like Lebanon

\begin{tabular}{|c|c|c|c|c|c|c|c|c|c|c|c|}
\hline \multirow[t]{3}{*}{ Variable } & \multicolumn{8}{|c|}{ Type of smoker } & \multirow[t]{3}{*}{$P$-value } & \multirow{2}{*}{\multicolumn{2}{|c|}{$\begin{array}{c}\text { Total } \\
(n=425)\end{array}$}} \\
\hline & \multicolumn{2}{|c|}{$\begin{array}{l}\text { Non-smoker } \\
\quad(n=183)\end{array}$} & \multicolumn{2}{|c|}{$\begin{array}{l}\text { Cigarettes } \\
(n=81)\end{array}$} & \multicolumn{2}{|c|}{$\begin{array}{c}\text { WP } \\
(n=75)\end{array}$} & \multicolumn{2}{|c|}{$\begin{array}{l}\text { Mixed } \\
(n=86)\end{array}$} & & & \\
\hline & No. & $\%$ & No. & $\%$ & No. & $\%$ & No. & $\%$ & & No. & $\%$ \\
\hline PDRD & 11 & 6.0 & 7 & 8.6 & 11 & 14.7 & 14 & 16.3 & 0.03 & 43 & 10.1 \\
\hline Allergy/asthma & 5 & 2.7 & 5 & 6.1 & 6 & 8.0 & 7 & 8.1 & 0.03 & 23 & 5.4 \\
\hline Chronic bronchitis & 4 & 2.2 & 2 & 2.4 & 4 & 5.3 & 7 & 8.1 & & 17 & 4.0 \\
\hline $\begin{array}{l}\text { Chronic bronchitis } \\
\text { symptoms }\end{array}$ & 27 & 14.8 & 30 & 37.0 & 20 & 26.7 & 36 & 41.9 & $<0.001$ & 113 & 26.6 \\
\hline $\begin{array}{l}\text { Ever used mucolytic for } \\
\text { chronic expectoration }\end{array}$ & 9 & 4.9 & 7 & 8.6 & 7 & 9.3 & 22 & 25.6 & $<0.001$ & 45 & 10.6 \\
\hline
\end{tabular}

المجلة الصحية لشرق المتوسط، منظمة الصحة العالمية، المجلد الخامس عشر، العدد Y، 9 +. 
Table 5 Dose-effect relationship between respiratory disease and exclusive water pipe consumption in Lebanon

\begin{tabular}{|c|c|c|c|c|c|c|}
\hline \multirow[t]{3}{*}{ Condition/WP exposure } & \multicolumn{4}{|c|}{ Respiratory disease } & \multirow[t]{3}{*}{ OR } & \multirow{3}{*}{$\begin{array}{c}\text { Trend test } \\
P \text {-value }\end{array}$} \\
\hline & \multicolumn{2}{|c|}{ No } & \multicolumn{2}{|c|}{ Yes } & & \\
\hline & No. & $\%$ & No. & $\%$ & & \\
\hline$\overline{P D R D}$ & & & & & & 0.012 \\
\hline $0 \mathrm{WP} /$ week & 171 & 94.0 & 11 & 6.0 & 1.00 & \\
\hline $1 \mathrm{WP} /$ week & 25 & 92.6 & 2 & 7.4 & 1.24 & \\
\hline 2-6 WP/week & 17 & 81.0 & 4 & 19.0 & 3.66 & \\
\hline > $6 \mathrm{WP} /$ week & 22 & 81.5 & 5 & 18.5 & 3.53 & \\
\hline $\begin{array}{l}\text { PDRD cumulative } \\
\text { exposure (WP years) }\end{array}$ & & & & & & 0.016 \\
\hline 0 & 173 & 93.5 & 12 & 6.5 & 1.00 & \\
\hline $1-3.5$ & 20 & 90.9 & 2 & 9.1 & 1.44 & \\
\hline $4-28$ & 23 & 88.5 & 3 & 11.5 & 1.88 & \\
\hline$>28$ & 19 & 79.2 & 5 & 20.8 & 3.79 & \\
\hline Chronic bronchitis & & & & & & 0.002 \\
\hline 0 WP/week & 156 & 85.2 & 27 & 14.8 & 1.00 & \\
\hline 1WP/week & 23 & 85.2 & 4 & 14.8 & 1.00 & \\
\hline 2-6 WP/week & 15 & 71.4 & 6 & 28.6 & 2.31 & \\
\hline$>6 \mathrm{WP} /$ week & 17 & 63.0 & 10 & 37.0 & 3.40 & \\
\hline $\begin{array}{l}\text { Chronic bronchitis } \\
\text { cumulative exposure }^{a}\end{array}$ & & & & & & 0.0002 \\
\hline 0 & 159 & 85.5 & 27 & 14.5 & 1.00 & \\
\hline $1-3$ & 19 & 86.4 & 3 & 13.6 & 0.93 & \\
\hline $4-28$ & 20 & 76.9 & 6 & 23.1 & 1.77 & \\
\hline$>28$ & 13 & 54.2 & 11 & 45.8 & 4.98 & \\
\hline
\end{tabular}

smoke WP and cigarettes indiscriminately, and there should be more concern regarding mixed smokers and those who switched from cigarettes to WPs $[23,24]$.

Concerning the dependence profile in WP smokers, since the majority smoked less than 7 WPs/week and could refrain from smoking WPs for several days, and 91\% smoked for pleasure, for social reasons or by habit, WP smoking appears to reflect mainly the third component of dependence: social dependence [25].

Our results also indicate that WP smoking may be a risk factor for chronic respira- tory disease and symptoms, as is cigarette smoking. There was no difference between these 2 categories of smokers, but there was a difference for PDRD between exclusive WP smokers and absolute non-smokers. This should be regarded with caution because the patients themselves reported that they had PDRD, which increases the likelihood of information bias. However, WPs being considered less harmful than cigarettes by smokers $[6,20,26]$ allows us to conclude a non-differential bias. The limitation is less robust for the question addressing symptoms of chronic bronchitis, 
Table 6 Multivariate analysis for water pipe (WP) smoking and respiratory diseases and symptoms in Lebanon

\begin{tabular}{|c|c|c|c|}
\hline Variable & OR $_{a}$ & $95 \% \mathrm{Cl}$ & $P$-value \\
\hline \multicolumn{4}{|l|}{ WP smoking } \\
\hline Older age & 0.98 & $0.96-0.99$ & 0.016 \\
\hline Working & 3.83 & $1.67-8.77$ & 0.002 \\
\hline City residence & NR & & \\
\hline Marital status & NR & & \\
\hline Smokers at home & 1.90 & $1.54-2.34$ & $<0.001$ \\
\hline Smokers at work & NR & & \\
\hline Cigarette smoking & 1.72 & $1.04-2.78$ & 0.03 \\
\hline Low education & 2.69 & $1.09-6.62$ & 0.03 \\
\hline \multicolumn{4}{|c|}{ Physician diagnosed respiratory disease } \\
\hline WP smoking & 1.95 & $0.99-4.05$ & 0.05 \\
\hline Older age & NR & & \\
\hline Working & NR & & \\
\hline City residence & NR & & \\
\hline Unmarried status & 0.12 & $0.02-0.74$ & 0.02 \\
\hline Smokers at home & 1.37 & $1.06-1.76$ & 0.02 \\
\hline Smokers at work & NR & & \\
\hline Cigarette smoking & 1.14 & $0.41-2.28$ & 0.71 \\
\hline Low education & NR & & \\
\hline \multicolumn{4}{|l|}{ Reported chronic bronchitis } \\
\hline WP smoking & 1.89 & $1.16-3.07$ & 0.01 \\
\hline Older age & 1.02 & $1.00-1.03$ & 0.04 \\
\hline Never worked & NR & & \\
\hline Village residence & 0.19 & $0.06-0.62$ & 0.006 \\
\hline Marital status & NR & & \\
\hline Smokers at home & NR & & \\
\hline Smokers at work & NR & & \\
\hline Cigarette smoking & 2.62 & $1.61-4.26$ & $<0.001$ \\
\hline Low education & 2.51 & $1.09-5.74$ & 0.03 \\
\hline Intermediate education & 1.87 & $1.11-3.18$ & 0.02 \\
\hline \multicolumn{4}{|c|}{ Mucolytic use for chronic expectoration } \\
\hline WP smoking & 3.07 & $1.49-6.36$ & 0.002 \\
\hline Older age & 1.04 & $1.01-1.06$ & 0.003 \\
\hline Never worked & NR & & \\
\hline Village residence & 5.29 & $1.85-15.11$ & 0.002 \\
\hline Marital status & $N R$ & & \\
\hline Smokers at home & 1.27 & $0.97-1.67$ & 0.08 \\
\hline Smokers at work & NR & & \\
\hline Cigarette smoking & 1.45 & $0.70-2.97$ & 0.32 \\
\hline Low education & 0.23 & $0.06-0.88$ & 0.03 \\
\hline Intermediate education & $N R$ & & \\
\hline
\end{tabular}


which included a high degree of precision [14]: WP smoking was independently associated with chronic bronchitis according to multivariate analysis and dose-effect relationship. No difference was found between exclusive WP smokers and cigarette smokers in this regard. An additive effect could explain what was seen in mixed smokers where chronic bronchitis symptoms were more frequent than in exclusive WP smokers. The use of mucolytics to improve cough and sputum production had the same distribution pattern as chronic bronchitis, and mixed smokers used more mucolytics than exclusive WP smokers and cigarette smokers. In Lebanon, it has been noticed in pharmaceutical practice that people with chronic productive cough use mucolytics as over-the-counter drugs instead of seeking medical advice; this may be an indication of underdiagnosed chronic bronchitis.

Our study had several weaknesses. Cross-sectional data do not allow evaluating over time, but the dose-effect relationship decreases the impact of this problem on causality. The telephone interview method may also be a source of selection bias, since telephone owners can be of a higher socioeconomic status than non-owners. In addition, recall bias is possible, as for all questionnaire-based epidemiological studies. However, these biases are nondifferential, and may only direct the results towards the null. On the other hand, we could not draw conclusions about nicotine dependence despite the fact that a minority of WP smokers in this population had signs of dependence.

\section{References}

1. K. Chaouachi. Tabacologie du narguilé. Revue alcoologie, 1999, 21(1/83): 8-9.

2. Radwan GN et al. Review on water-pipe smoking. Journal of the Egyptian Society of Parasitology, 2003, 33(3 Suppl.):1051-71.

3. Maziak $W$ et al. Tobacco smoking using a waterpipe: a re-emerging strain in a global epidemic. Tobacco control, 2004, 13:327-33.

4. Afifi Soweid RA. Lebanon: water pipe line to youth. Tobacco control, 2005, 14:363-4.

5. Kandela P. Narghile smoking keeps Arabs in wonderland. Lancet, 2000, 356(30):1175.

6. Varsano $\mathrm{S}$ et al. [Water-pipe tobacco smoking among school children in Israel: frequencies, habits and attitudes]. Harefuah, 2003, 142(11):736-41 [in Hebrew].

7. Macaron $\mathrm{C}$ et al. Urinary cotinine in narguila or chicha tobacco smokers. Lebanese medical journal, 1997, 45(1):19-20.
8. Shihadeh A, Saleh R. Polycyclic aromatic hydrocarbons, carbon monoxide, "tar", nicotine in the mainstream smoke aerosol of the narguile water-pipe. Food \& chemical toxicology, 2005, 43(5):65561.

9. Nuwayhid IA et al. Narghile (hubble-bubble) smoking, low birth weight, and other pregnancy outcomes. American journal of epidemiology, 1998, 148(4):375-83.

10. Kiter $\mathrm{G}$ et al. Water-pipe smoking and pulmonary functions. Respiratory medicine, 2000, 94(9):891-4.

11. El Hakim IE, Uthman MA. Squamous cell carcinoma and keratoacanthoma of the lower lip associated with "Goza" and "Shisha" smoking. International journal of dermatology, 1999, 38(2):108-10.

12. Aydin A et al. Water-pipe smoking effects on pulmonary permeability using technetium-99mDTPA inhalation scintigraphy. Annals of nuclear medicine, 2004, 18(4):285-9. 
13. Huchon GJ et al. Chronic bronchitis among French adults: high prevalence and underdiagnosis. European respiratory journal, 2002, 20:806-12.

14. American Thoracic Society. Standards for the diagnosis and care of patients with chronic obstructive pulmonary disease. American journal of respiratory and critical care medicine, 1995, 152(5 Pt 2):S77-121.

15. Heatherton TF et al. The Fagerström Test for Nicotine Dependence: a revision of the Fagerström Tolerance Questionnaire. British journal of addictions, 1991, 86(9):1119-27.

16. Diagnostic and statistical manual of mental disorders, 4th ed. (DSM-IV). Washington DC, American Psychological Association, 1994.

17. Tamim $\mathrm{H}$ et al. Tobacco use by university students, Lebanon 2001. Addiction, 2003, 98(7):933-9.

18. Chaaya $M$ et al. Smoking among university students: a new tobacco epidemic. Nicotine \& tobacco research, 2004, 6(3):457-63.

19. Zoughaib S, Adib S, Jabbour J. Prevalence and determinants of water-pipe or narghuile use among students in Beirut's southern suburbs. Lebanese medical journal, 2004, 52(3):142-8.
20. Nuwaihed I, Sibai AM. Epidemiological review of selected diseases, injuries and risk factors in Lebanon. Beirut, American University of Beirut Publications, 2002.

21. Shihadeh A. Investigation of mainstream smoke aerosol of the narghile waterpipe. Food \& chemical toxicology, 2003, 41(1):143-52.

22. Maziak W, Ward KD, Eissenberg T. Factors related to frequency of narguile (water-pipe) use: the first insights on tobacco dependence in narguile users. Drug and alcohol dependence, 2004, 76(1):101-6.

23. Chaouachi K. A critical review of scientific literature on narghile (shisha, hookah, waterpipe) from its origins to date: the need for a comprehensive socio-anthropological, medical and pharmacological approach. Tabaccologia, 2005, 1:39-47.

24. Chaouachi K. Narghile, hookah in the 21st century: an overview of the scientific knowledge. Le courrier des addictions, 2004, 6(4):150-2.

25. Poland $B$ et al. The social context of smoking: the next frontier in tobacco control? Tobacco control, 2006, 15:59-63.

26. Asfar $\mathrm{T}$ et al. Comparison of patterns of use, beliefs, and attitudes related to water-pipe between beginning and established smokers. BMC public health, 2005, 5:19. 